\title{
"Old" and "new" contaminants and their management: learning from the past, looking to the future
}

\author{
Gillian Gibson · Andrew Cundy (D) N Nswana Kafwamfwa $\cdot$ Alex Stewart $(\mathbb{D}$
}

Received: 25 March 2021 / Accepted: 13 July 2021 / Published online: 9 August 2021

(C) The Author(s) 2021

\begin{abstract}
Within the 50 year lifetime of the Society for Environmental Geochemistry and Health (SEGH), we have seen a number of contaminants transfer from being the wonder chemical of their day through to becoming current contaminants of concern. This is also true for a variety of emerging contaminants such as plastic microbeads, pharmaceutical residues, and
\end{abstract}

fire retardant chemicals, amongst others. This thought piece discusses the risk associated with a range of these emerging contaminants, their global nature, how existing models and frameworks can be applied to deal with their impacts, and research and management gaps and challenges.

G. Gibson

Gibson Consulting and Training, Tarporley,

Cheshire CW6 0JH, UK

A. Cundy $(\bowtie)$

School of Ocean and Earth Science, University of

Southampton, Southampton SO14 3ZH, UK

e-mail: A.Cundy@soton.ac.uk

N. Kafwamfwa

Zambia Agriculture Research Institute, Mochipapa

Regional Research Station, Choma, Southern province,

Zambia

A. Stewart

College of Life and Environmental Sciences, University

of Exeter, Exeter EX4 4RJ, UK 


\section{Graphic Abstract}
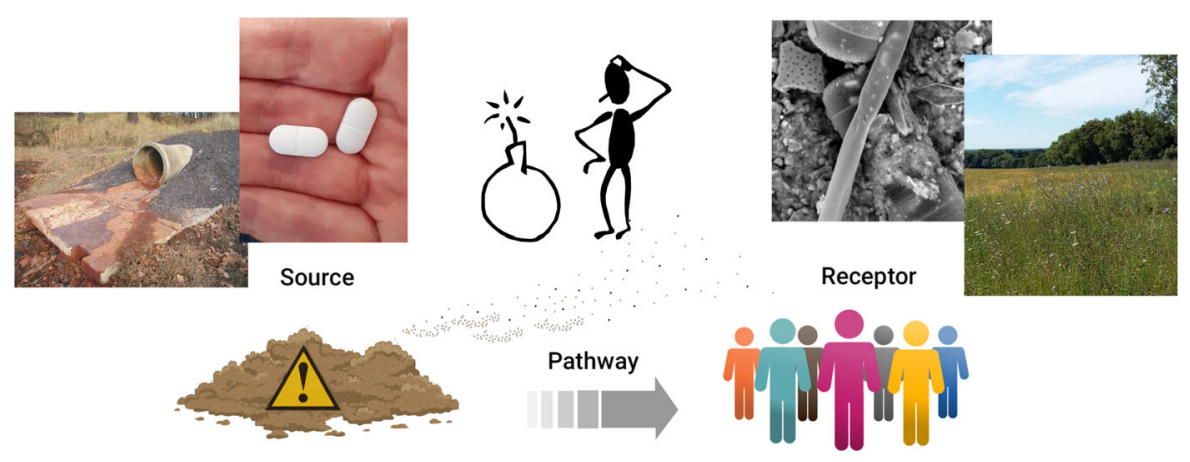

Keywords Emerging contaminants - Human health · Risk · Plastics · Pharmaceutical residues . Antimicrobial resistance

\section{Introduction}

In this 50th anniversary year of the Society for Environmental Geochemistry and Health (SEGH), the environment and human society are faced with a range of global challenges, from global heating to postpandemic recovery. In parallel, as part of the post1950 "Great Acceleration" (the dramatic, continuous and roughly simultaneous surge in growth rate across a large range of measures of human activity), we are seeing increased demands on natural resources. This includes so-called critical metals, used in a range of rapidly emerging industrial sectors such as renewable energies. Consequences include a change of geochemical cycling and transfer of these and other metals, and the increased development, use and release of new chemical compounds. Many new compounds are persistent and potentially bioaccumulative in the environment-so-called emerging contaminants.

SEGH itself has a long history of engaging with global issues at the interface of geochemistry, the environment and human health, such as the health risks of lead in soils, and arsenic in drinking waters. In this thought piece, we take a chronological approach, giving an historical perspective on our understanding of risk from both longer-recognised, or "old", contaminants (such as lead and arsenic) and from emerging, "new", contaminants (such as plastics and anti-inflammatory drugs), examining the journey to "now" (including development of international management frameworks, and frameworks for risk understanding and assessment), and assessing future trends and challenges. In particular, we focus on the risk associated with a range of emerging contaminants, how existing models and frameworks can be applied for dealing with these risks, and research and management gaps and challenges.

\section{"Old" and "new" contaminants}

One contaminant with which readers of EGAH will be familiar (and to which the Society has made important contributions) has been with us since the early stages of metal exploitation and use: lead. The toxicity of lead has long been recognised, as has that from a range of other metals and metalloids (such as arsenic, cobalt, chromium), with limits imposed on their use and, from both environmental and health viewpoints, their acceptable concentrations in waters, soils and other media. While we understand much about such "old" contaminants, much still remains to be learnt through constantly improving technology which enables measurement of differing chemical forms of an elementspeciation-and allows better understanding of the mobility, toxicity, origin or pathway of such an element.

Equally, as we increasingly manage the risk from these elements, and reduce or replace their use, we need to ensure we do not create new risks or problems. Taking mercury out of switchgear, where it did an excellent job as an insulating material, replacing it 
with a less satisfactory substance, sodium hexafluoride (Ottersbach, 2019), created a completely different problem: widespread release of a gas which is a major contributor to global heating. This example is one of many which highlight the adverse side of the law of unintended consequences. Although referring to economics, the following quote from the French economic journalist Frédéric Bastiat (1801-1850) distinguished between the "seen" and the "unseen" (Bastiat, 1848):

There is only one difference between a bad economist and a good one: the bad economist confines himself to the visible effect; the good economist takes into account both the effect that can be seen and those effects that must be foreseen. (emphasis added)

It can equally apply to environmental consequences.

However, it is a third effect, the unforeseeable and unanticipated consequences, which are arguably even more important, and which we need to recognise when they occur (de Zwart, 2015). An example would be the fact that recycling is seen to be a good thing. Certainly, from the conservation of raw materials and the avoidance of land contamination this is undoubtedly the case. However, the presence of flame retardants in children's toys which have been manufactured from recycled plastic, probably from WEEE (waste electrical and electronic equipment) (Turner et al., 2021), is an unanticipated consequence-though it could be argued that insufficient risk assessment had been applied to the process, and the consequences should have been foreseen.

Within the lifetime of SEGH, we have seen some contaminants evolve from being the wonder chemical of their day through to becoming current contaminants of concern. Well-known examples are DDT, chlorofluorocarbons, neonicotinoids and glyphosate, the latter two of which are still controversial. This evolution may be due to technical advances in our ability to detect and track inorganic and organic contaminants in the environment or biological systems at trace (but still potentially toxic) levels, and/or time taken to observe or recognise their wider ecosystem or health risks. There will always be such emerging contaminants, which in time become old or established ones. The battle is how to prevent novel entities such as plastic microbeads, nanoparticles and new chemicals such as fire retardants from becoming persistent problems of the future. As an example, the heatresistant "forever chemicals" PFOS (perfluoro-octane sulfonate), PFOA (perfluoro-octanoic acid) and related per-fluorinated substances have been widely used in stain-resistant and non-stick coatings, and fire fighting foams. PFOS has been prohibited in the European Union since 2008. Falling serum levels in the USA indicate that exposure to these "forever" chemicals can be reduced (ATSDR, 2020) though they remain chemicals of concern in the UK (Public Health England, 2018a). Despite being chemicals in Annexe B of the Stockholm convention (discussed below), they continue to appear in consumer products, most recently in cosmetics (Whitehead et al., 2021) and remain of global concern. Furthermore, the safety of their replacements is now being challenged (Minet, 2021).

\section{The journey to "now"}

Global protection and cooperation

The formation of the United Nations post-World War Two enabled the development of internationally binding treaties, for the protection of all. The simultaneous creation of the World Health Organization (WHO) enabled research to be carried out which considers the health of people at a global level, and to inform the development of appropriate treaties. Perhaps the most notable and best known is the Montreal Protocol of 1985, banning the production of chlorofluorocarbons (CFCs) for their ozone-depleting actions, and to which have been added a number of other ozone-depleting substances. For the purpose of this paper possibly the most relevant treaty is the Stockholm Convention (United Nations, 2019). This bans or restricts the production and trading of existing chemicals which are known to have an impact on human health.

Under the European REACH (Registration, Evaluation, Authorisation and Restriction of Chemicals) regulations (European Commission, 2006), European countries aim to implement the UN "Precautionary" (United Nations Global Compact, 2000) and "Polluter Pays" (OECD, 1992) principles: REACH requires the producer of novel (i.e., new and unproven) chemicals to register them before they come to market, and demonstrate that they do not cause harm, either to the 
wider environment, or to human health. This is a reversal of previous approaches, whereby chemicals were freely traded, and have proved difficult to remove from circulation despite there being ample evidence of their damaging nature.

Each UN convention (or protocol-the term is used interchangeably) is overseen by its own committee. The committee comprises parties, that is, representatives from member states or countries which are signatories to the convention. It is worth noting that three committees of the parties, Rotterdam (importation of hazardous chemicals), Stockholm (restriction of production and use of persistent organic chemicals) and Basel (restriction of movement of hazardous waste between countries), recognise the synergy which exists between the three conventions, and that joint meetings can bring great benefits (Synergies, 2018, and linked webpages). Recommendations from the committees are discussed at the "conference of the parties" which are held on an annual basis: perhaps the most widely recognised recent one (UNEP, 2015) is COP21 which gave rise to the Paris agreement on limiting global temperature increase.

Monitoring and modelling pollutant migration

The "source, pathway, receptor" model is often used within the environmental community, including relevant industry, to evaluate the risk to the environment (or human health) which may result from loss of control of a substance during the manufacturing process, or following its release to land or water in the contaminated land sector. However, it is a model which is increasingly being deployed to backtrack anthropogenic materials found throughout the environment, acting as a detective to determine the point of production or release, and thus the polluter responsible for creating a problem.
Anthropogenic substances migrate from the points of manufacture, use, and disposal, and are now found all across the globe (Jamieson et al., 2019), from the deepest ocean trenches to the remote poles. They pose a continuing threat to the health of most species including humans, as many continue to bioaccumulate (become concentrated within living organisms) and biomagnify (become more concentrated higher up a food chain). Microplastics, which carry endocrine disrupting chemicals, have been found in the placentas of humans, and have migrated to the foetal side (Ragusa et al., 2021), while engineered nanoparticles (used in hundreds of consumer products, finding increasing use in food industries and with potential for improving pharmaceutical treatments) are capable of crossing cell membranes and inhibiting cell function, or accumulating in organs (including the brain), resulting in neurotoxicity, pulmonary toxicity, vascular dysfunction, genotoxicity, and immunotoxicity (Wang et al., 2021). In the human body, endocrine disrupting chemicals and air pollution particles may act as obesogens, amongst other health effects (de Cock \& van de Bor, 2014; Yang et al., 2019)—see Case Study 1: Plastics.

Chemical transformations occur naturally in the environment. This has happened throughout Earth's history, for example rain falling through the atmosphere, picking up gases as it passes, creating acid rain. However, unlooked-for chemical reactions arise from the interaction of anthropogenic chemicals with the "wild" environment. Well-known examples are the interactions between chlorofluorocarbons (CFCs) and ozone in the stratosphere leading to ozone depletetion, and the diurnal reaction between NOx and polycyclic aromatic hydrocarbons (PAH) creating photochemical smog (Scorer, 1990). It is important to recognise that chemicals which may be developed in the future may initially appear to be benign, but the potential to hybridise into something altogether undesirable cannot be ignored. 


\begin{abstract}
Case Study 1: Plastics
The period since the 1950s has seen a rapid acceleration of the environmental release and disposal of plastics, and plastics pollution is now widely recognised as being one of the planet's most pressing environmental issues. This is a global problem - plastics now comprise the majority of marine debris and represent its most durable and persistent part (Maximenko et al., 2019). Once in the environment, plastics will break down into smaller and smaller particles, through microplastics to nanoplastics; microplastics are also produced and released directly in a range of industrial and other activities. While larger plastics can cause direct organism mortality through entanglement and ingestion, there are concerns over the ecosystem-level impacts particularly of microplastics and nanoplastics, which can be more easily ingested by organisms in lower trophic levels and can also act as vectors for other chemical and biological contaminants. The bulk of marine plastics are land-derived, typically through river inputs, and mismanaged landbased solid wastes are estimated to contribute significantly to environmental plastics pollution, particularly in lower-and middle-income economies. Globally, solid wastes are generated faster than any other environmental pollutant; without significant infrastructure improvements to waste management it is estimated that the cumulative release of plastics will increase by an order of magnitude by 2025. Despite extensive research, there are still numerous uncertainties over the impacts of plastics ingestion on humans via food and other routes; this is a subject of ongoing debate in academic and other literature.
\end{abstract}

Not all problematic substances have their origins as chemicals designed to impact the wider environment, but may be focused, with the intention of improving human and animal health. Widely used anti-inflammatory drugs such as diclofenac (See Case Study 2:
Diclofenac) illustrate the complex interaction of source, pathway, and receptor, acknowledging that pathways may be a receptor in their own right, and that pathways may be multiple, complex and varied.

Case study 2: Diclofenac

Diclofenac is a drug which is widely available over the counter (i.e. without the use of a doctor's prescription) in many but not all countries. It is a highly effective antiinflammatory, used for a wide variety of complaints, but most notably arthritis.

In India cattle are revered by Hindus. Consequently, they are looked after well. This includes treating them with diclofenac when they become elderly and arthritic. However, this has led to unexpected consequences, which required long investigation. Those same cattle, when they die, are fed upon by vultures. The vultures also perform a vital service in the death of humans who follow the Zoroastrian religion. Zorastrians place their dead in towers, where the vultures have traditionally cleaned the bones. However, it was noted that the vulture numbers were declining, thus the dead were no longer being 'serviced'. Dead animals were also accumulating in the streets. Investigations in neighbouring Pakistan led to an understanding that the anti-inflammatories caused acute kidney failure in the vultures, though this took time to be accepted (Richards et al., 2018). Loss of vultures equals an increase in animal carcasses which in turn leads to increased disease. This was the first clear case of major ecological damage caused by a pharmaceutical product (Gorman, 2009). Other vulture species in other parts of the world are also at threat from this and other pharmaceuticals (Jiminez-Lopez et al., 2021). 
Wider environmental impact

There is also an impact on plant health resulting from the human and veterinary use of pharmaceutical products (Schmidt \& Redshaw, 2015). Anti-inflammatories are excreted by humans and animals, in urine, either directly to groundwater, or via sewage treatment works into wider water bodies. River estuaries around the UK have recently been found to be carrying a heavy load of ibuprofen and related painkillers (University of Hull, 2019). The same applies to the estuary of the Elbe, in northern Germany (Wiegel et al., 2004). These are not alone in being impacted by pharmaceutical materials (Pait et al., 2006). Water used for plant irrigation may be the carrier of these drugs directly to the plants, or the water may be derived from natural uptake via groundwater. The plants are able to accumulate various pharmaceuticals (Herklotz et al, 2010). The failure to provide protection for the environment may have knock-on effects with stunted crops providing less food, and that which is available being contaminated with pharmaceutical residues. Further, the overuse of antibiotics in livestock farming contributes to an increasing number of microbial species resistant to antimicrobial control, generating further risks to animal and human health. See Case Study 3: Antimicrobial resistance (AMR).

Case Study 3: Antimicrobial resistance (AMR)

Another emerging contaminant group in the food system, which affects resource poor countries in Africa and elsewhere as much as resource rich countries, are antibiotics. The overuse of antibiotics in humans and livestock has become a major focus, including for the WHO. This results in resistance by an increasing number of microbial species to antimicrobial control, and threatens the effective prevention and treatment of an everincreasing range of infections caused by bacteria, parasites, viruses and fungi (WHO, 2020; WHO, 2021). Antimicrobials play an essential role in combatting infectious diseases in human and veterinary medicine, agriculture and the environment. AMR is now recognized as one of the most significant global threats to public health. However, the WHO global situation analysis report of 2015 noted that information on the true extent of the problem of AMR was limited in the African Region. Work is underway to remedy this (TDR, 2021). A situation analysis and needs assessment on AMR conducted in 2010-2011, funded by the Bill and Melinda Gates Foundation, highlighted some factors that contribute to AMR in Zambia (APUA, 2014), including: easy access to antibiotics without prescription; poor laboratory capacity to conduct antimicrobial susceptibility testing; and poor quality of some antibiotics. However, the situation is exacerbated by more than just human behaviour or limited resources. AMR is also associated with some metals (Nguyen 2019) and has been observed during the treatment of troops returning from the battlefield (Bazzi, 2020). Perhaps this should not be a surprise: bacteria are known to colonise the oceanic deep vents where they utilise metals as a nutrient. While there remains an urgent need to generate evidence-based information on the human use and abuse of antibiotics in agriculture in order to facilitate behavioural changes on the appropriate use of antimicrobials to safeguard human and animal health, the connection between $A M R$ and metals is a potential pathway driving global antimicrobial resistance that would not be addressed through improved antibiotics stewardship, and which also needs further exploration (Bazzi, 2020). 

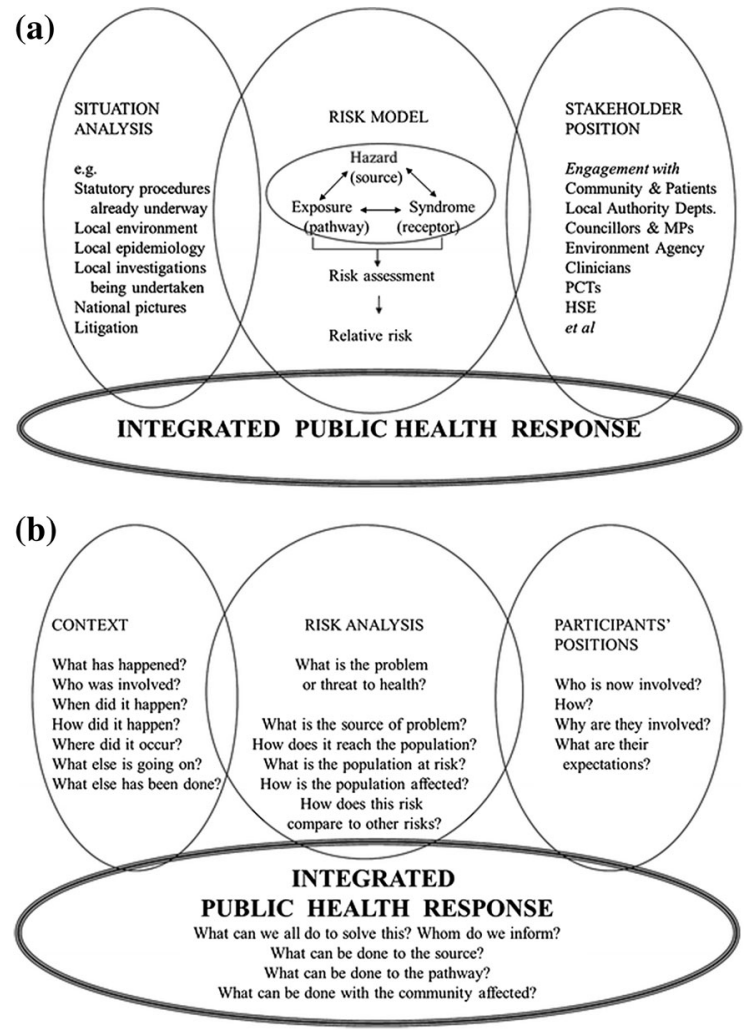

Fig. 1 Integrated Public health risk assessment and response. a Outline risk assessment. b Application: questions to help the practical application. Source: Mahoney et al., 2015; used with permission

Sewage treatment works were developed for the prevention of faecal material entering waterways. There is nothing within the system which prevents the migration of pharmaceutical residues, nor a range of other chemical residues arising from direct excretion or manufacturing processes. Indeed, the sewage treatment works provide the very conditions for spontaneous chemistry to occur: large vats of diverse material being mixed, in a warm setting, in the presence of bacteria. Further, not all communities have the luxury of the control of waste materials. Many people still live without a functioning latrine; some chemical industries discharge waste directly into nearby streams and rivers. These wastes find their way into groundwater, aquifers, and potentially into the ocean.

While a range of compounds are relatively mobile and persistent, entering marine systems, some of the drugs adhere to sediment. Examination of sediment cores has demonstrated the presence of a wide variety of anthropogenic chemicals adhering to sediment at any one time. Their mobilisation and desorption is dependent upon the chemical under consideration, sediment composition, and the various physicochemical, and biological, processes occurring on and within the sediment. The need for understanding of this interplay between the aquatic environment and geological surfaces is of importance for the health of species which dwell and feed in sediment, and those which predate upon them.

\section{Consideration and management of risk}

It is this uncertainty of material, and unpredictability of outcome, which requires a coordinated approach to protection of human health, such as that used successfully in the North West of England (UK) for two decades or more (Mahoney et al., 2015) (Fig. 1). At its heart, this model again makes use of the sourcepathway-receptor model, which is essentially focused on the environment, but overlays it with the human health impact, of hazard, exposure, syndrome.

The WHO has stated that almost a quarter of human disease globally has an environmental cause (WHO, 2006). It can be seen from the model (Fig. 1 (cf. Figure 3)) that there are many contributing factors in the field of understanding and prevention of disease. However, there are unseen tensions which the model can help explore: the desire for employment, job creation, and for business to make money. When a business can see the opportunity to make money, it may be at any cost, including that of its workers. Historically, it has been well-documented that workers exposed to phosphorous in match factories suffered from "phossy jaw", asbestos exposure has led to mesothelioma across many occupations such as construction workers and dockers, and silicosis and pneumoconiosis affect miners. Improved working conditions responding to legislation have either eradicated these conditions (phossy jaw) or reduced exposure (asbestos, silicosis, pneumoconiosis) in some areas (Stewart, 2020).

Vigilance is required by all involved parties to ensure that emerging industries and technologies do not replace historical problems with fresh ones, that the "polluter pays" principle is embedded within planning, and that there is not a presumption of jobs at any cost and associated impact-neither to the workers themselves nor to the wider public. 


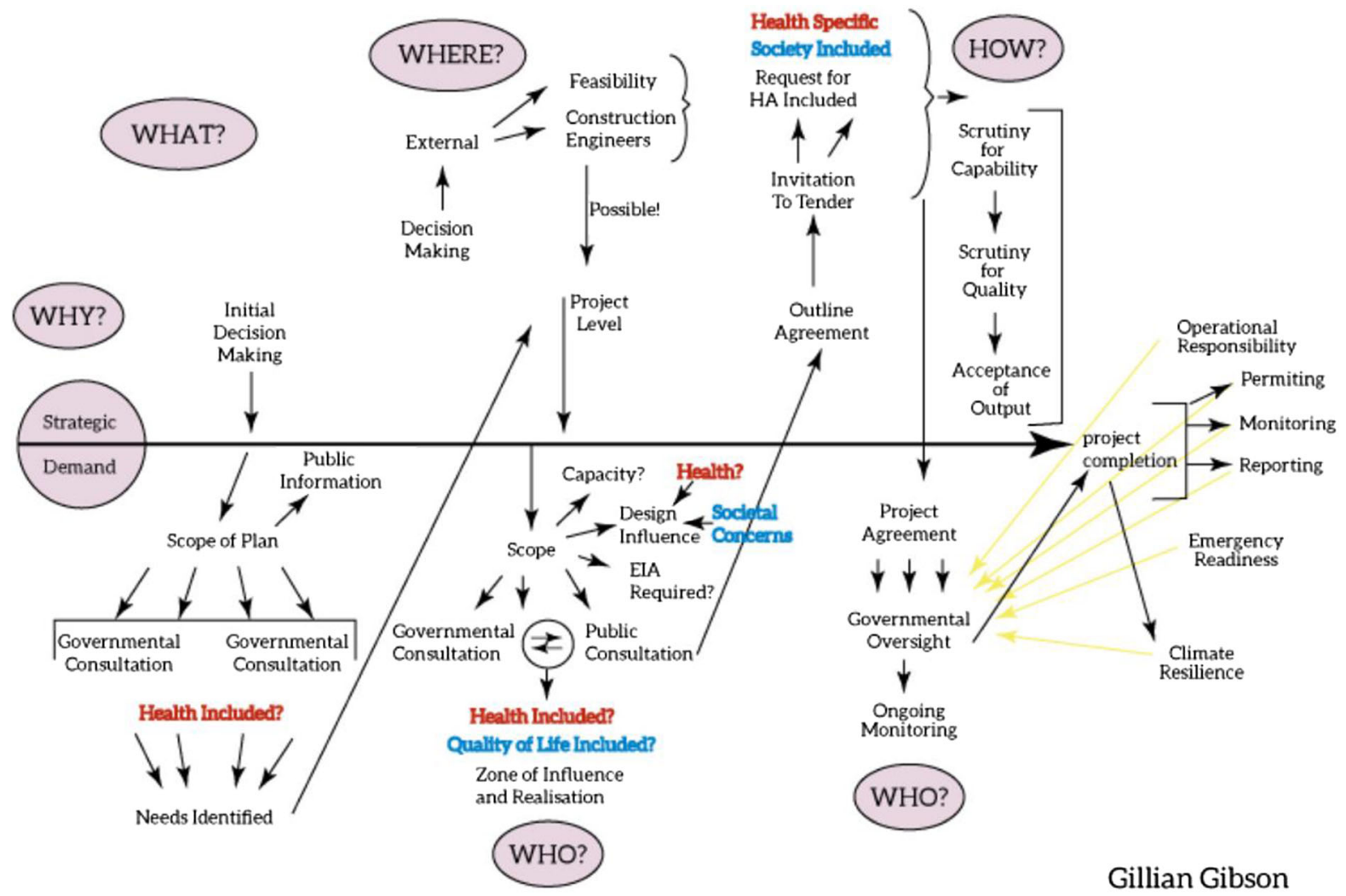

Fig. 2 Evaluation of the impact on health from strategic decision-making, through planning, to operational control and decommissioning. Gibson, G. Author, this paper

These principles are embedded in the process of Health Impact Assessment. Understanding that a coordinated approach is required to prevent pollution is at the heart of Gibson's model (Fig. 2). Evaluating the impact on health along the process of strategic decision-making, through planning, to operational control and finally decommissioning is essential if future contamination is to be prevented.

For example, in order to have a strategy for clean air, a strategic decision to manufacture electric vehicles would recognise that they rely on battery power. This in turn is likely to require several battery manufacturing sites, as well as car manufacturing sites. The batteries require lithium, cobalt and other elements. The mining of these elements will have an impact on the miners, and on the communities where the mining takes place (Entwistle et al., 2019). Some of these will be positive (employment) and some will be negative (ground contamination, inhalation).

Transport of the mined materials will have an environmental impact at a global level, contributing to global heating. Construction and deployment of the manufacturing bases will impact the local environment-again, there will be positive and negative consequences. As the batteries and vehicles are in use, and when they become spent, there will be further impact at a societal level. What happens to the batteries? Are the incorporated metals retrieved and recycled in order to prevent them being released into the wider environment, (with further requirements for a recycling plant, with associated local planning) or are they lost from sight? Currently, a range of rare and/ or valuable metals are locked up in unused mobile phones, meaning that further material needs to be mined to fill the gap. Global thinking, cooperation, strategy and policy are required to ensure that the wunderkind of today is not the contaminant of the future (Pagano, 2016).

Since the industrial revolution, the demand for jobs has been an over-riding one. As society observes the damage which has accrued through this approach, with the disadvantage of that approach not always falling 
on its beneficiaries, there is a strong demand for accountability and cleaner manufacturing. This is manifest as investors seek to divest from traditional "dirty" industry. But it should be remembered that just because something appears to be clean does not mean that it is benign.

There is an additional concern. As high-income countries seek to clean up and operate more effectively, illegal transfer of WEEE to countries with a less well-developed or robust legal system creates an impact in a new region causing new environmental diseases, such as in Agbogbloshie in Ghana (The Guardian, 2014), where previously pristine wetlands are now polluted beyond recognition.

Dismantling of WEEE and burning of cables in order to retrieve valuable metals has led to an environmental catastrophe; fire retardants, products of combustion (dioxins and similar) and metals are released in an uncontrolled manner. The lives of all the residents are impacted due to the contamination of their crops, and the acrid air from the burning of the waste. Those who carry out the "recycling" have increased risk of cancers and other diseases following exposure to a toxic mix of chemicals (WHO, 2015). These recycled materials are then the very ones which find their way into children's toys, plastic plates, and other consumer goods.

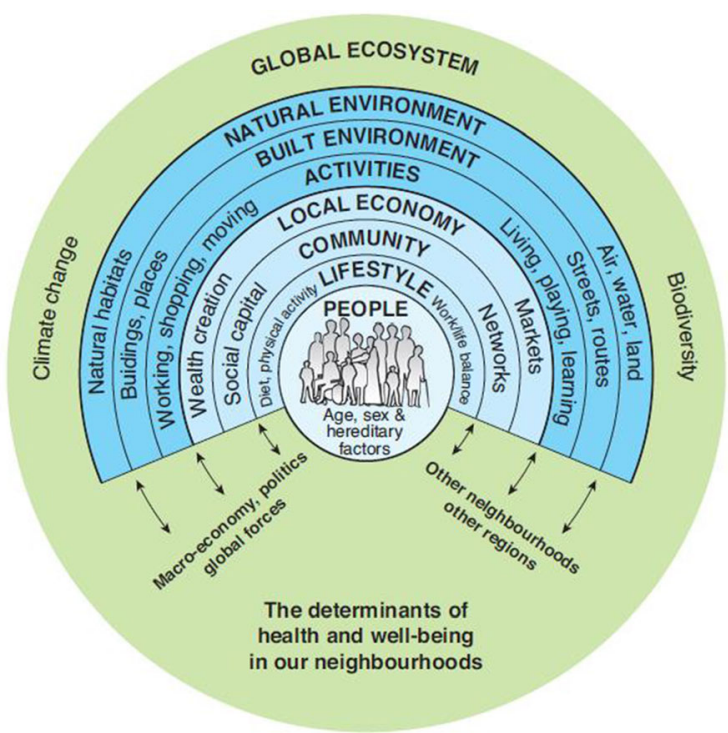

Fig. 3 Determinants of health and well-being from the individual level to the global (Barton and Grant, 2006, reproduced with permission)

\section{Future actions and cooperation}

Human health itself is a complex response to an uncertain set of parameters: at its most basic, each person is a novel entity by virtue of their genetic makeup. We are still only just touching the surface of our understanding of epigenetics (Carey, 2012). Consequently, understanding our relationship to our wider environment is challenging and evolving.

Barton and Grant (2006) enhanced the original onion skin model (Dahlgren \& Whitehead, 1991) which recognises that while people are at the centre of their own lives, their wider environmental and social conditions also influence their health, often with little personal control (Fig. 3). Accordingly, we need to ensure that the environment is as benign as possible, and that it is health-giving rather than a source of ill health.

The only effective way to provide protection for all people and animals is to prevent the escape of future designer chemicals, wastes, residues, etc., into the environment. Before chemicals, of whatever sort, are released into the environment, we need to be sure that a future "wicked problem" is not being created. A wicked problem may be considered to be a complex problem with no clear right or wrong, good or bad answer and which changes as we engage with it. It needs recognition in the first place as such a class of problem, and then it needs a multi-agency or multiprofessional approach, with a willingness to observe continually the problem and adapt the response as appropriate until a satisfactory result is reached or the problem is recognised as beyond our ability to answer. If the latter, the problem may require disaggregation into smaller problems, which can be addressed more effectively (Mahoney et al., 2015).

For this to happen, wider cooperation between the various disciplines, such as already occurs between researchers associated with SEGH, needs to become the norm, in order to foster greater understanding of the risks and opportunities. The risks need to be communicated clearly to policy makers and funders to inform sound decision-making.

Longitudinal health studies are difficult to conduct, but are an excellent way to be sure of identifying adverse effects which may take many years to emerge. Sometimes they happen accidentally ("natural experiments", such as the follow-up of the cohort exposed to radiation as a result of the disaster at Chernobyl, 
Hatch \& Cardis, 2017). Longitudinal studies are important not only to observe effects on the people exposed to a variety of environmental contaminants, but also on the following generation. A female foetus develops all the eggs while in utero, it subsequently becomes fertilised when the female is of reproductive age. Exposure in utero to environmental pollutants may have an effect some forty or more years later as the next generation (possibly two) reaches maturity, exhibiting complex and poorly understood syndromes, when contemporary physicians may not necessarily be aware of historical issues. There is also (as yet) limited evidence of transfer of epigenetic impacts through four generations of male progeny (Weinhold, 2006). Clearly prevention is better than cure.

In the wider environment, top predators bioaccumulate contaminants with catastrophic results. Lactating females pass these contaminants to their offspring in their milk. Orca calves are thought to have died as the burden of PCBs in the maternal milk is too contaminated for them to process (Desforges et al., 2018). This is a very visible problem as cetaceans wash up on beaches and can be subject to post-mortem. It may be happening elsewhere in the natural world but less visibly. Domesticated animals are likely to be protected from some of the problems as they are fed regulated food. Wild animals may be exposed to a cocktail of pollutants which have a subclinical effect but which, in the fullness of time, can show substantial impact, as they transfer across the generations. Longitudinal studies on animal cohorts may help to unravel the aetiology of environmental impacts which perhaps give rise to human health problems.

\section{Discussion: for the future-synergies and trade- offs}

In science, there are many synergies and trade-offs. As an example, the fight against global heating is driving a global move away from fossil fuel use. This is significant as currently, at both national and international levels, the human population and the rest of the global biota are exposed to poor air quality derived from burning of fossil fuels, whether for heating or transport (WHO, 2013). Particulate matter less than ten microns in diameter $\left(\mathrm{PM}_{10}\right)$ is known to enter the body and cause damage to the circulatory system.
Smaller particles of 2.5 microns $\left(\mathrm{PM}_{2.5}\right)$ are able to enter the blood stream and travel around the body: they are associated with miscarriages, early birth, low birthweight, Parkinson's disease, stroke, infertility and diabetes type 2 . The smaller particles of only one micron $\left(\mathrm{PM}_{1}\right)$ are known to cross the blood brain barrier and have been implicated in Alzheimers and other neurological diseases (Ascher et al., 2017; Finch, 2018). A permanent shift away from fossil fuel will drive a reduction in fossil fuel-derived fine particles, though there will still remain anthropogenic particulates from the breakdown of vehicle parts (brakes, tyres, windscreen wipers), dust from mining and construction activities, and other (including natural) contributions to particles and aerosols. All of these will need to be managed at a global level if human and other biotic health is to be protected.

Similarly, the changed pattern of behaviour at national and global levels due to the Covid-19 pandemic has provided the opportunity to observe changes in air quality resulting from altered (reduced, by and large) patterns of manufacturing and travel. The requirement for wearing of masks to prevent inhalation of viral aerosols may also be providing protection from more general air pollution. However, spending a greater amount of time in our homes, where masks are not being worn, is likely to be exposing us to a different set of contaminants indoors. Indeed, indoor air may pose as many problems as outdoor air. Harrad and colleagues have been studying household dust for several years and found it to be contaminated with fire retardants (Tao et al., 2016). These are emitted from electrical equipment, furnishing, and carpets, to which the fire retardants (linked to endocrine disruption, developmental issues, cancers and other adverse health effects) have been applied. A paradox is embedded here; it may not be possible to see the results of either of these changes as they are masked by the adverse health effects of the pandemic virus itself.

Not all air pollution is anthropogenic in nature; volcanic eruptions for example also contribute to poor air quality, as do natural dust storms. Humans have no direct control over these events, though the health impact can be large. A combination of anthropogenic and naturally occurring particulate matter has the potential to cause long lasting health impacts (Citris Policy Lab., 2019), and also impact food and other crops-the load of particulates contributes to a reduction in photosynthesis, with an attendant 
reduction in biomass. This may become critical in crop production (Prajapati, 2012). Additionally, aerosols, whether naturally occurring (e.g. generated by wind passing over the ocean, particles picked up by mists) or human-induced (e.g. crop spraying, vapour from unburnt aircraft fuel), contribute to ill health by enabling intake of mixed material into the body. A mixture of volatile organic compounds, metals, and carbonaceous material all take their toll on the body, at a cellular level as well as a system level (Pardo et al., 2020). Increasingly, the awareness of the metalliferous content, and chemical reactivity of the aerosols both within the aerosols themselves and then within biological systems, indicates a need for a coordinated approach to control of emissions, in addition to a global responsibility for end-of-life action on waste (Despeisse et al., 2015).

\section{Concluding thoughts}

Consideration of the multiple determinants of health (Fig. 3) in conjunction with some of the issues raised here demonstrates the need for evaluation of the effect of environmental exposure, whether to deliberate or accidental pollutants, on the health of humans: (a) from preconception to senescence; (b) in the home, workplace, and wider world; (c) in the impact on the food and water they consume; and (d) in and through the very air they breathe. The use of the sourcepathway-receptor approach needs to be considered across time and space as well as in close proximity and immediacy.

Furthermore, two complementary concepts need to be kept in mind, (1) One Health (WHO, 2017) and (2) an all hazards approach. One Health is an approach to designing and implementing programmes, policies, legislation and research in which multiple sectors communicate and work together to achieve better public health outcomes (cf. the approach in Fig. 2 and related text). It includes the responses to address the challenge of AMR, made more urgent by the recognition of environmental inputs to AMR (Case Study 3). As such, One Health goes beyond the WHO (2017) description of infectious diseases since environmental pollution affects more than just humans. The all hazards approach (Norris et al., 2020) is still developing, but aims to replace the long-standing reductionist focus on individual hazards with a broad view across disciplines, factors and issues to the commonalities in understanding and response.

In this article, we have described the effects on the global environment which may be attributable to pollution. There is a financial cost associated with these negative effects. The UK government through Public Health England have estimated the costs to the health service of poor air quality (Public Health England, 2018b). For 2017, it was estimated to be $£ 42.9$ million, and considered to be reaching $£ 5.3$ billion by 2035 , unless action is taken. That is one country, one pollutant group. At a global level Cohen (2017), arguing cogently for investment in sustainability management to reduce the costs of pollution, quoted The Lancet Commission on pollution and health (Landrigan et al., 2017):

In 2015, diseases caused by air, water and soil pollution were responsible for 9 million premature deaths, that is $16 \%$ of all global death. Exposures to contaminated air, water and soil kill more people than smoking, hunger, natural disasters, war, AIDS, or malaria.

This eclipses the number of deaths caused by the Covid pandemic to date. The Environmental Protection Agency (EPA) of America (EPA, 2011) has indicated that return on investment to prevent pollution is at a rate of thirty to one. Similarly, WHO (2010) notes that the cost-benefit from reducing lead hazards in the USA outweighs that of investment in vaccines, which have long been described as the single most cost-beneficial health intervention, by a factor between 17 and 220. The question needs to be posed that with such rates of return, why isn't everyone investing? If that return was to appear in the portfolio of an investment company investors would be clamouring for a share.

There are protocols in place which have global agreement through the United Nations and supported by WHO which are intended to prevent trade of harmful substances. The Sustainable Development Goals (SDGs) (United Nations, 2015) are intended to enable nations to trade in ways which do not negatively impact the environment and require good governance at a business, government and personal level. For both "old" and "new" contaminants, the global sustainability agenda and post-Covid recovery offers opportunities and challenges for managing the 
health risks of air, soil, sediment and water pollution, and reducing global inequalities in exposure.

Geochemists and health professionals in SEGH, and beyond, need to keep warning of consequences of unregulated chemicals. Biologists and health professionals need to keep warning of the implications of the use of untested materials. More data, including robust, comparable, measurements of environmental and other media (at often very low concentrations) are needed to drive more effective policy, regulation and risk management, while also recognising that data interpretation may change with time, and a strong narrative today may be challenged in the light of new information in the future. Key needs here are to provide accessible technology, methods and data to monitor effectively across low and middle income, as well as higher income, countries, and to link data across disciplines. All of us need to collaborate across and beyond our disciplines to inform policy, regulation and practice, and support evidence-based, holistic and integrated risk and response approaches which will benefit the whole planet as well as ourselves.

Acknowledgements The authors thank two anonymous reviewers for helpful and constructive comments which improved the manuscript.

Authors' contributions GG, AC and AS developed the concept and structure of the paper, and all authors contributed to the drafting, review and editing of the paper. All authors have approved the version of the paper submitted for publication, and have agreed the stated order of authorship.

Funding Preparation of this manuscript was undertaken using the authors' own resources, or as part of their standard employment.

Availability of data and material All data and material are presented within the publication, or are cited from the referenced literature.

\section{Declaration}

Conflict of interest GG runs the consulting and training company Gibson Consulting and Training. The remaining authors declare that the research was conducted in the absence of any commercial or financial relationships that could be construed as a potential conflict of interest. The views presented in this publication are those of the authors, and do not necessarily reflect those of their employers.

Open Access This article is licensed under a Creative Commons Attribution 4.0 International License, which permits use, sharing, adaptation, distribution and reproduction in any medium or format, as long as you give appropriate credit to the original author(s) and the source, provide a link to the Creative Commons licence, and indicate if changes were made. The images or other third party material in this article are included in the article's Creative Commons licence, unless indicated otherwise in a credit line to the material. If material is not included in the article's Creative Commons licence and your intended use is not permitted by statutory regulation or exceeds the permitted use, you will need to obtain permission directly from the copyright holder. To view a copy of this licence, visit http://creativecommons.org/licenses/by/4.0/.

\section{References}

APUA. (2020). Gates Foundation project: Antibiotic resistance situation analysis and needs assessment (ARSANA) in Uganda and Zambia. Alliance for the Prudent Use of Antibiotics. Retrieved 18 March 2021 from https://apua. org/gates-foundation-project/.

Ascher, M., Costa, L. G. (Eds). (2017). Advances in neurotoxicology. Environmental factors in neurodegenerative diseases. Cambridge MA, and Oxford, UK: Academic Press.

ATSDR. (2020). Per- and Polyfluoroalkyl Substances (PFAS) and Your Health. PFAS in the U.S. Population. USA: Agency for Toxic Substances and Disease Registry. Retrieved 18 June 2021 from https://www.atsdr.cdc.gov/ pfas/health-effects/us-population.html.

Barton, H., \& Grant, M. (2006). A health map for the local human habitat. The Journal for the Royal Society for the Promotion of Health, 126(6), 252-253. https://doi.org/10. 1177/1466424006070466

Bastiat, F. (1848). Selected essays on political economy. In G. B. de Huszar, (Ed.), Selected essays on political economy. (Trans: Seymour Cain). 1995. Irvington-on-Hudson, NY: The Foundation for Economic Education Inc. Retrieved January 1, 2021 from https://fokt.pw/file-selected-essayson-political-economy.pdf.

Bazzi, W., Abou Fayad, A. G., Nasser, A., Haraoui, L. P., Dewachi, O., Abou-Sitta, G., Nguyen, V. K., Abara, A., Karah, N., Landecker, H., Knapp, C., McEvoy, M. M., Zaman, M. H., Higgins, P. G., \& Matar, G. M. (2020). Heavy metal toxicity in armed conflicts potentiates AMR in A. baumannii by selecting for antibiotic and heavy metal co-resistance mechanisms. Frontiers in Microbiology. https://doi.org/10.3389/fmicb.2020.00068

Carey, N. (2012). The Epigenetics Revolution. Icon Books. ISBN 978-184831-347-7.

Citris Policy Lab. (2019). Health, Wildfires and Climate Change in California. Berkley: California Institute for Energy and Environment. http://citris-uc.org/wp-content/uploads/ 2019/10/Health-Wildfires-and-Climate-Change-inCalifornia_October-2019.pdf.

Cohen, S. (2017). The Human and Financial Cost of Pollution. Earth Institute Columbia University. Retrieved 17 March 2021 from https://blogs.ei.columbia.edu/2017/10/23/thehuman-and-financial-cost-of-pollution/.

Dahlgren, G., \& Whitehead, M. (1991). Policies and Strategies to promote social equity in health. Stockholm Institute of Future Studies. 
de Cock, M., \& van de Bor, M. (2014). Obesogenic effects of endocrine disruptors, what do we know from animal and human studies? Environment International, 70, 15-24. https://doi.org/10.1016/j.envint.2014.04.022

de Zwart, F. (2015). Unintended but not unanticipated consequences. Theory and Society, 44, 283-297. https://doi.org/ 10.1007/s11186-015-9247-6

Desforges, J.-P., Hall, A., McConnell, B., Rosing-Asvid, A., Barber, J. L., Brownlow, A., De Guise, S., Eulaers, I., Jepson, P. D., Letcher, R. J., Levin, M., Ross, P. S., Samarra, F., Víkingson, G., Sonne, C., \& Dietz, R. (2018). Predicting global killer whale population collapse from PCB pollution. Science, 361(6409), 1373-1376. https:// doi.org/10.1126/science.aat1953

Despeisse, M., Kishita, Y., Nakano, M., \& Barwood, M. (2015). Towards a circular economy for end-of-life vehicles: A comparative study UK-Japan. Procedia CIRP, 29, 668-673. https://doi.org/10.1016/j.procir.2015.02.122

Entwistle, J., Hursthouse, A., Marinho Reis, P., \& Stewart, A. (2019). Metalliferous mine dust: Human health impacts and the potential determinants of disease in mining communities. Current Pollution Reports., 5(3), 67-83. https:// doi.org/10.1007/s40726-019-00108-5

EPA. (2011). Benefits and costs of the Clean Air Act 1990-2020, the second prospective study. United States Environmental Protection Agency. Clean Air Act Overview. Retrieved 17 March 2021 from https://www.epa.gov/ clean-air-act-overview/benefits-and-costs-clean-air-act1990-2020-second-prospective-study.

European Commission. (2006). REACH. Environment. Retrieved 8 March 2021 from https://ec.europa.eu/ environment/chemicals/reach/reach_en.htm.

Finch, C. E. (2018). The role of global air pollution in aging and disease. Reading smoke signals. London UK, and San Diego, CA: Academic Press.

Gorman, J. (2004). A drug used for cattle is said to be killing vultures. New York Times. Retrieved 8 March 2021 from https://www.vepachedu.org/TSJ/vultures.htm.

Hatch, M., \& Cardis, E. (2017). Somatic health effects of Chernobyl: 30 years on. European Journal of Epidemiology, 32(12), 1047-1054. https://doi.org/10.1007/s10654017-0303-6

Herklotz, P. A., Gurung, P., Vanden Heuvel, B., \& Kinney, C. A. (2010). Uptake of human pharmaceuticals by plants grown under hydroponic conditions. Chemosphere, 78(11), 1416-1421. https://doi.org/10.1016/j.chemosphere.2009. 12.048

Jamieson, A. J., Brooks, L. S. R., Reid, W. D. K., Piertney, S. B., Narayanaswamy, B. E., \& Linley, T. D. (2019). Microplastics and synthetic particles ingested by deep-sea amphipods in six of the deepest marine ecosystems on Earth. Royal Society Open Science. https://doi.org/10. 1098/rsos. 180667

Jiminez-Lopez, O., Ponder, J., Nault, A., \& Bueno, I. (2021). Non-steroidal anti-inflammatory drugs (Nsaids) and their effect on Old World vultures: A scoping review. Journal of Raptor Research. Available at https://doi.org/10.3356/ JRR-20-30/451685/Non-Steroidal-Anti-InflammatoryDrugs-Nsaids-and.

Landrigan, P. J., Fuller, R., Acosta, N. J. R., Adeyi, O., Arnold, R., Basu, N., Baldé, A. B., Bertollini, R., Bose-O’Reilly, S.,
Bouord, J. I., Baldé, A. B., Bertollini, R., Bose-O'Reilly, S., Boufford, J. I., Breysse, P. N., Chiles, T., Mahidol, C., Coll-Seck, A. M., Cropper, M. L., Fobil, J., Fuster, V., Greenstone, M., Haines, A., Hanrahan, D., Hunter, D., Khare, M., Krupnick, A., Lanphear, B., Lohani, B., Martin, K., Mathiasen, K. V., McTeer, M. A., Murray, C. J. L., Ndahimananjara, J. D., Perera, F., Potočnik, J., Preker, A. S., Ramesh, J., Rockström, J., Salinas, C., Samson, L. D., Sandilya, K., Sly, P. D., Smith, K. R., Steiner, A., Stewart, R. B., Suk, W. A., van Schayck, O. C. P., Yadama, G. N., Yumkella, K., \& Zhong, M. (2017). The Lancet Commission on pollution and health. The Lancet, 391, 462-512. https://doi.org/10.1016/S0140-6736(17)32345-0

Mahoney, G., Stewart, A. G., Kennedy, N., Whitely, B., Turner, L., \& Wilkinson, E. (2015). Achieving attainable outcomes from good science in an untidy world: Case studies in land and air pollution. Environmental Geochemistry \& Health, 37, 689-706. https://doi.org/10.1007/s10653-015-9717-9

Maximenko, N., Corradi, P., Law, K. L., van Sebille, E., Garaba, S. P., Lampitt, R. S., Galgani, F., Martinez-Vicente, V., Goddijn-Murphy, L., Veiga, J. M., Thompson, R. C., Maes, C., Moller, D., Löscher, C. R., Addamo, A. M., Lamson, M. R., Centurioni, L. R., Posth, N. R., Lumpkin, R., et al. (2019). Toward the integrated marine debris observing system. Frontiers in Marine Science, 6, 447. https://doi. org/10.3389/fmars.2019.00447

Minet, L., Blum, A., Fernández, S. R., Rodgers, K. M., Singla, V., Soehl, A., \& Diamond, M. L. (2021). High production, low information: We need to know more about polymeric flame retardants. Environmental Science and Technology. https://doi.org/10.1021/acs.est.0c08126

Nguyen, C. C., Hugie, C. N., Kile, M. L., \& Navab-Daneshmand, T. (2019). Association between heavy metals and antibiotic-resistant human pathogens in environmental reservoirs: A review. Frontiers of Environmental Science \& Engineering, 13(3), 1-7. https://doi.org/10.1007/ s11783-019-1129-0

Norris, J., Wright, N., Fagan, L., Mayner, L., \& Murray, V. (2020). Taking an all-hazards approach to tackling global disaster risk-an important step towards implementing the UN Sendai Framework for Disaster Risk Reduction. EGU General Assembly 2020, Online, 4-8 May 2020, EGU2020-22175. Retrieved 17 March 2021 from https:// doi.org/10.5194/egusphere-egu2020-22175.

OECD. (1992). The polluter-pays principle. OECD analyses and recommendations. Environmental Directorate, Organisation for Economic Co-operation and Development, Paris. Retrieved 17 March 2021 from http://www.oecd.org/ officialdocuments/publicdisplaydocumentpdf/?cote= OCDE/GD\%2892\%2981\&docLanguage=En

Ottersbach, N. (2019). Switchgear uses Sf6 the world's most potent greenhouse gas how do we regulate it? Energy Post.eu. Retrieved 9 March 2021 from https://energypost. eu/grid-switchgear-uses-sf6-the-worlds-most-potentgreenhouse-gas-how-do-we-regulate-it/.

Pagano, G. (2016). Rare earth elements in human and environmental health: At the crossroads between toxicity and safety. Jenny Stanford Publishing. ISBN 9789814745000.

Pait, A. S., Warner, R. A., Hartwell, S. I., Nelson, J. O., Pacheco, P. A., \& Mason, A. L. (2006). Human use pharmaceuticals in the estuarine environment: A survey of the Chesapeake 
Bay, Biscayne Bay and Gulf of the Farallones. NOAA Technical Memorandum NOS NCCOS 7. Silver Spring, Md.: U.S. Dept. of Commerce, National Oceanic and Atmospheric Administration, National Ocean Service, National Centers for Coastal Ocean Science, Center for Coastal Monitoring and Assessment. https://purl.fdlp.gov/ GPO/LPS100339. (p. 21).

Pardo, M., Qiu, X., Zimmermann, R., \& Rudich, Y. (2020). Particulate matter toxicity Is Nrf2 and mitochondria dependent: The roles of metals and polycyclic aromatic hydrocarbons. Chemical Research in Toxicology, 33(5), 1110-1120. https://doi.org/10.1021/acs.chemrestox. $0 \mathrm{c} 00007$

Prajapati, S. (2012). Ecological effect of airborne particulate matter on plants. Environmental Skeptics and Critics, 1:12-22. https://www.researchgate.net/publication/ 257836928_Ecological_effect_of_airborne_particulate_ matter_on_plants.

Public Health England. (2018b). New tool calculates NHS and social care costs of air pollution. Chemical and Environmental Hazards. News story. Retrieved 17 March 2021 from https://www.gov.uk/government/news/new-toolcalculates-nhs-and-social-care-costs-of-air-pollution

Public Health England. (2018a). PFOS and PFOA: Health effects, incident management and toxicology. Retrieved 9 March 2020 from https://www.gov.uk/government/ publications/pfos-and-pfoa-properties-incidentmanagement-and-toxicology

Ragusa, A., Svelato, A., Santacroce, C., Catalano, P., Notarstefano, V., Carnevali, O., Papa, F., Rongioletti, M. C. A., Baiocco, F., Draghi, S., D’Amore, E., Rinaldo, D., Matta, M., \& Giorgini, E. (2021). Plasticenta: First evidence of microplastics in human placenta. Environment International. https://doi.org/10.1016/j.envint.2020. 106274

Richards, N. L., Gilbert, M., Taggart, M., \& Naidoo, V. (2018). A cautionary tale: Diclofenac and its profound impact on vultures. Encyclopedia of the Anthropocene, 5, 247-255. https://doi.org/10.1016/B978-0-12-809665-9.09990-0

Schmidt, W., \& Redshaw, C. H. (2015). Evaluation of biological endpoints in crop plants after exposure to non-steroidal anti-inflammatory drugs (NSAIDs): Implications for phytotoxicological assessment of novel contaminants. Ecotoxicology and Environmental Safety, 112, 212-222. https://doi.org/10.1016/j.ecoenv.2014.11.008

Scorer, R. S. (1990). Meteorology of air pollution: Implications for the environment and its future. UK: Ellis Horwood. ISBN 0-13-577230-3

Stewart, A. G. (2020). Mining is bad for health: A voyage of discovery. Environmental Geochemistry \& Health., 42, 1153-1165. https://doi.org/10.1007/s10653-019-00367-7

Synergies. (2018). Joint meeting of the bureaux of the conferences of the Parties to the Basel, Rotterdam and Stockholm conventions. Synergies among the Rotterdam, Basel and Stockholm Conventions. Retrieved 8 March 2021 from http://www.brsmeas.org/Decisionmaking/JointBureaux/ JointBureauxMeetings/JointBureauxMeeting2018/ Overview2018/tabid/7516/language/en-US/Default.aspx.

Tao, F., Abdallah, M.A.-E., \& Harrad, S. (2016). Emerging and legacy flame retardants in UK indoor air and dust: Evidence for replacement of PBDEs by emerging flame retardants? Environmental Science and Technology, 50(23), 13052-13061. https://doi.org/10.1021/acs.est. $6 \mathrm{~b} 02816$

TDR. (2021). SORT IT. Special programme for research and training in tropical diseases. Retrieved 17 March 2021 from https://www.who.int/tdr/capacity/strengthening/sort/ en/.

The Guardian. (2014). Agbogbloshie: The world's largest e-waste dump-in pictures. Retrieved 8 March 2021 from https://www.theguardian.com/environment/gallery/2014/ feb/27/agbogbloshie-worlds-largest-e-waste-dump-inpictures.

Turner, A., Scott, J. W., \& Green, L. A. (2021). Rare earth elements in plastics. Science of the Total Environment. https://doi.org/10.1016/j.scitotenv.2021.145405

UNEP. (2015). Sustainable innovation forum. Retrieved 9 March 2021 from https://www.cop21paris.org/.

United Nations. (2015). The 17 Goals. Department of economic and cocial affairs. Sustainable Development. Retrieved 8 March 2021 from https://sdgs.un.org/goals

United Nations. (2019). Overview. Stockholm convention. Retrieved 9 March 2021 from http://www.pops.int/ TheConvention/TheConvention/Overview/tabid/3351/ Default.aspx.

United Nations Global Compact. (2000). The power of principles. United Nations Global Compact. Retrieved 8 March 2021 from https://www.unglobalcompact.org/what-is-gc/ mission/principles.

University of Hull. (2019). Hight levels of pharmaceuticals found in the Humber Estuary. Retrieved 9 March 2021 from https://www.hull.ac.uk/work-with-us/more/mediacentre/news/2019/high-levels-of-pharmaceuticals-foundin-humber-estuary.

Wang, W., Wang, L., Mettenbrink, E. M., DeAngelis, P. L., \& Wilhelm, S. (2021). Nanoparticle toxicology. Annual Review of Pharmacology and Toxicology, 61, 268-289. https://doi.org/10.1146/annurev-pharmtox-032320110338

Weinhold, B. (2006). Epigenetics: The science of change. Environmental Health Perspectives. https://doi.org/10.1289/ ehp.114-a160

Whitehead, H. D., Venier, M., et al. (2021). Fluorinated compounds in North American cosmetics. Environmental Science \& Technology Letters. https://doi.org/10.1021/acs. estlett. $1 \mathrm{c} 00240$

WHO. (2006). Almost a quarter of all disease caused by environmental exposure. World Health Organization Media Centre. Retrieved 9 March 2021 from https://www.who. int/mediacentre/news/releases/2006/pr32/en/.

WHO. (2010). Childhood lead poisoning. Geneva, Switzerland: World Health Organisation. Retrieved 18 March 2021 from http://www.who.int/ceh/publications/leadguidance.pdf.

WHO. (2013). Health Effects of Particulate matter: Policy implications for countries in eastern Europe, Caucasus and central Asia. World Health Organization. Retrieved 9 March 2021 from https://intranet.euro.who.int/_data/ assets/pdf_file/0006/189051/Health-effects-of-particulatematter-final-Eng.pdf.

WHO. (2015). Waste and human health: Evidence and needs. World Health Organization. WHO meeting report, 5-6 November 2015, Bonn, Germany. Retrieved 17 March 
2021 from https://www.euro.who.int/_data/assets/pdf_ file/0003/317226/Waste-human-health-Evidence-needsmtg-report.pdf.

WHO. (2017). What is 'One Health'? One Health. World Health Organization. Retrieved 8 March 2021 from https://www. who.int/news-room/q-a-detail/one-health.

WHO. (2020). Antimicrobial Resistance. World Health Organization. WHO Africa. Retrieved 17 March 2021 from https://www.afro.who.int/health-topics/antimicrobialresistance.

WHO. (2021). Antimicrobial resistance. World Health Organization. Retrieved 18 March 2021 from https://www.who. int/health-topics/antimicrobial-resistance.

Wiegel, S., Aulinger, A., Brockmeyer, R., Harms, H., Löffler, J., Reincke, H., Schmidt, R., Stachel, B., von Tümpling, W.,
\& Wanke, A. (2004). Pharmaceuticals in the river Elbe and its tributaries. Chemosphere, 57(2), 107-126. https://doi. org/10.1016/j.chemosphere.2004.05.017

Yang, Z., Song, Q., Li, J., \& Zhang, Y. (2019). Air pollution as a cause of obesity: Micro-level evidence from Chinese Cities. International Journal of Environmental Research and Public Health, 16, 4296. https://doi.org/10.3390/ ijerph16214296

Publisher's Note Springer Nature remains neutral with regard to jurisdictional claims in published maps and institutional affiliations. 